\title{
CORRELAÇ̃̃o DE PEARSON E ANÁLISE DE TRILHA IDENTIFICANDO VARIÁVEIS PARA CARACTERIZAR PORTA-ENXERTO DE Pyrus communis L.
}

\author{
Pearson correlation and path analysis identifying variables for the \\ characterization of Pyrus communis L. rootstock
}

\author{
Simone Padilha Galarça ${ }^{1}$, Cláudia Simone Madruga Lima², Gustavo da Silveira ${ }^{3}$, Andreia De Rossi Rufato ${ }^{4}$
}

\begin{abstract}
RESUMO
Objetivou-se, no presente trabalho, através de correlação de Pearson e análise de trilha, identificar variáveis para caracterizar porta-enxertos ananizantes para a cultura da pereira (Pyrus communis L.). Neste experimento foram utilizadas 49 plantas de pereira, plantadas nos canteiros do Departamento de Fitotecnia da FAEM/UFPel. As plantas foram avaliadas na época do seu crescimento vegetativo, segundo parâmetros descritos em instruções do Ministério da Agricultura, Pecuária e Abastecimento. Pela correlação de Pearson, as variáveis VP, NRP, HCP e FCNPRCL se destacaram. Na análise de trilha, a variável número de lenticelas obteve maior efeito positivo sobre VP, NRP e FCNPRCL, a variável ramificação do ramo demonstrou-se com efeito positivo sobre HCP, sendo essas duas variáveis consideradas eficazes no processo de seleção de porta-enxerto juntamente com as variáveis básicas.
\end{abstract}

Termos para indexação: Pereira, variáveis básicas, processo de seleção, descrições morfológicas.

\begin{abstract}
The objective of this work was to identify, through the Pearson correlation and path analysis, variables to characterize rootstocks suitable for the cultivation of the pear (Pyrus communis L.). In this experiment 49 pear specimens were used, planted in flowerbeds at the Phytotechny Department. The plants were evaluated at the time of growth, according to parameters described in the instructions of the Ministério da Agricultura, Pecuária e Abastecimento. According to the Pearson correlation, the variables VP, NRP, ETA and FCNPRCL stood out. In path analysis, the variable number of lenticels had a more positive effect on VP, NRP and FCNPRCL, variable branch of the industry had a more positive effect on ETA. Both variables were considered effective in the process of selection of rootstock together with the basic variables.
\end{abstract}

Index terms: Pear, basic variables, selection process, morphological descriptions.

(Recebido em 29 de janeiro de 2009 e aprovado em 22 de fereveiro de 2010)

\section{INTRODUÇÃO}

A pereira pertence à família Rosaceae, subfamília Pomoideae e gênero Pyrus. Compreende mais de 20 espécies, todas nativas da Europa e da Ásia. As espécies mais importantes são: Pyrus communis L., P. pyrifolia (Burm) Nakai, P. ussuriensis Maxim., P. bretschneideri Rehder, P. betulifolia Bunge., P. pashia Bich.-Ham ex D. Don., $P$. nivalis Jacq. e P. calleryana Decne (Perazzolo, 2006).

A pereira (Pyrus communis L.) é uma espécie de clima temperado de grande importância nacional, tendo em vista seu alto consumo, sendo a fruta de clima temperado mais consumida no Brasil, depois da maçã e do pêssego. No entanto, quando se compara a produção brasileira dessas frutas, é a menos expressiva, o que impõe ao país a condição de segundo maior importador, com cerca de 162 mil toneladas, em 1997 (João et al., 2002; Madail \& Reichert, 2002).
A utilização das espécies Pyrus calleryana e P. betulaefolia como porta-enxertos, apesar de apresentarem grande rusticidade, imprimem grande vigor à planta, dificultando a realização de tratos culturais, proporcionando pomares desuniformes e tardios para entrar em produção (Barbosa et al., 1994).

O melhoramento genético é uma das modernas tecnologias de produção que merece destaque, pois tem contribuído significativamente para o desenvolvimento da fruticultura brasileira, com ganhos significativos de produtividade e qualidade de frutos. A grande maioria dos estudos objetiva a seleção e/ou criação de cultivares copa adaptada às condições de clima temperado, enquanto que, no caso de porta-enxertos, os estudos são bastante incipientes (Giacobbo et al., 2007).

Em termos de utilização no melhoramento, os portaenxertos de Pyrus apresentam características importantes como a grande rusticidade, o que constitui uma qualidade

\footnotetext{
${ }^{1}$ Universidade Federal de Pelotas, Faculdade de Agronomia Eliseu Maciel - Departamento de Fitotecnia - 96010900 - Pelotas, RS sgalarca@superig.com.br

2Universidade Federal de Pelotas, Faculdade de Agronomia Eliseu Maciel - Departamento de Fitotecnia - Pelotas, RS

${ }^{3}$ Universidade Federal de Pelotas, Faculdade de Agronomia Eliseu Maciel - Departamento de Fitomelhoramento - Pelotas, RS

${ }^{4}$ Embrapa Uva e Vinho - Estação Experimental de Fruticultura Temperada - Vacaria, RS.
}

Ciênc. agrotec., Lavras, v. 34, n. 4, p. 860-869, jul./ago., 2010 
desejável frente a ambientes adversos, tais como áreas úmidas e mal drenadas, temperaturas elevadas, pragas e moléstias do solo e proporcionam maior produtividade às pereiras enxertadas. E ainda, os porta-enxertos originados de pereira comum são considerados mais tolerantes ao frio e menos suscetíveis à clorose férrica (Wertheim, 2002).

Lacey (1973) estudou correlações fenotípicas entre características vegetativas e frutíferas em morangueiro e, observou que existem dois grupos aos quais as primeiras estão relacionadas com as segundas: aquelas associadas ao número de frutos, como o número de folhas no outono anterior e aquelas associadas ao tamanho do fruto, como o tamanho da planta na estação precedente.

O conhecimento das correlações entre caracteres é muito importante, pois o melhorista tem condições de orientar a seleção de forma indireta para aqueles caracteres de interesse. Convém enfatizar que os estudos de correlações entre caracteres não permitem tirar conclusões sobre as relações de causa e efeito sendo necessário seu desdobramento, por meio da análise de trilha. Wright (1921) idealizou os estudos da análise de trilha, que é um desdobramento das correlações estimadas em efeitos diretos e indiretos sobre uma variável básica. A decomposição da correlação é dependente do conjunto de variáveis estudadas, da importância de cada uma e das possíveis inter-relações expressas em diagrama de trilha (Ribeiro Junior, 2001).

A análise de trilha vem sendo empregada com sucesso no melhoramento genético vegetal de diversas culturas, e vem auxiliando no processo de formulação de procedimentos adequados de seleção (Carvalho et al., 1999; Caierão et al., 2001; Kurek et al., 2001; Furtado et al., 2002; Coimbra et al., 2005; Vieira et al., 2007). Entretanto ainda são escassos trabalhos dessa natureza envolvendo plantas frutíferas.

Objetivou-se, no presente trabalho, através de correlação da Pearson e análise de trilha, identificar variáveis para caracterizar porta-enxertos ananizantes para a cultura da pereira.

\section{MATERIAL E MÉTODOS}

O experimento foi conduzido em 2007, nas dependências da Universidade Federal de Pelotas, Faculdade de Agronomia Eliseu Maciel, nos canteiros experimentais do Departamento de Fitotecnia, localizado no Campus Universitário de Pelotas, RS, Brasil.

Neste experimento foram utilizadas 49 plantas de pereira (Pyrus communis), plantadas nos canteiros do Departamento de Fitotecnia. As plantas foram avaliadas na época do seu crescimento vegetativo, segundo parâmetros descritos em instruções do Ministério da Agricultura, Pecuária e Abastecimento que consta no Diário Oficial da União de 21/01/2003, seção 1, páginas 1 a 3 (Of. El. nº 010/SARC).

As características observadas foram:

Vigor (VP), Número de ramos (NRP), Hábito de crescimento (HCP), Ramo de um ano: tipo de crescimento (TC), Ramo de um ano: ramificação (RR), Ramo de um ano: comprimento do entrenó no terço médio do ramo (CETMR), Ramo de um ano: cor da epiderme na face exposta ao sol (CFES), Ramo de um ano: número de lenticelas (NL), Ramo de um ano: tamanho das lenticelas (TL), Ramo de um ano: forma das lenticelas (FL), Ramo do ano: pigmentação antociânica da extremidade apical em crescimento (PAEA), Ramo do ano: pubescência (no terço superior) (PR), Folha: posição em relação ao ramo (FPERR), Folha: perfil da secção transversal ao limbo (FPSTL), Folha: forma da base do limbo (FFBL), Folha: forma do ápice do limbo (excluindo a ponta) (FFAL), Folha: incisões na margem do limbo (FIML), Folha: curvatura da nervura central (vista de perfil) (FCNC), Folha: cor da nervura principal em relação à cor do limbo (face superior) (FCNPRCL), Folha: comprimento do pecíolo: (FCP), Folha: estípulas (EF).

Com relação às variáveis transformaram-se os dados para a escala logarítmica, em variáveis aleatórias contínuas atendendo assim às pressuposições do teste $t$. Após as transformações foi verificada a normalidade e a homogeneidade de variâncias através do teste shapirowilk e pelo teste bartlett.

As informações obtidas foram submetidas à estimativa dos coeficientes de correlação de Pearson (r) e os resultados mais significativos foram desdobrados e obtidos os coeficientes em análise de trilha, através do uso do programa computacional Genes (UFV) (Cruz, 2001).

O coeficiente de correlação de Pearson é representado pela letra $\mathrm{r}$ e assume valores de -1 a 1 . $(\mathrm{r}=1)$, representa a correlação perfeita e positiva entre duas variáveis, $(\mathrm{r}=-1)$, representa correlação perfeita negativa entre duas variáveis, ou seja, enquanto uma aumenta a outra diminui, à medida que se aproxima do 1 vai ficando perfeita a correlação.

O coeficiente de correlação de Pearson calcula-se segundo a seguinte fórmula:

$$
r=\frac{\sum_{i=1}^{n}\left(x_{i}-\bar{x}\right)\left(y_{i}-\bar{y}\right)}{\sqrt{\sum_{i=1}^{n}\left(x_{i}-\bar{x}\right)^{2}} \cdot \sqrt{\sum_{i=1}^{n}\left(y_{i}-\bar{y}\right)^{2}}},
$$

onde $\mathrm{x} 1, \mathrm{x} 2, \ldots$, xn e y1 , y2 ,..., yn são os valores medidos de ambas as variáveis. Para, além disso: 


$$
\bar{x}=\frac{1}{n} \cdot \sum_{i=1}^{n} x_{i} \quad \text { e } \quad \bar{y}=\frac{1}{n} \cdot \sum_{i=1}^{n} y_{i}
$$

São as médias aritméticas de ambas as variáveis.

A escolha das variáveis básica para a análise de trilha veio do estudo da matriz de correlação de Pearson, destacando as mais significativas a $1 \%$ de probabilidade de erro. E a metodologia utilizada foi a descrita por Cruz \& Regazzi (1997), em que os coeficientes de trilha foram obtidos pela equação: $\mathrm{Y}=\mathrm{Po} 1 \mathrm{X} 1+\mathrm{Po} 2 \mathrm{X} 2+\ldots+$ PonXn + $\mathrm{P}$ uem que $\mathrm{Y}$ é o coeficiente da variável dependente; $\mathrm{Po}$ é o coeficiente de efeito direto; $X$ é variável independente explicativa; $\mathrm{P}$ u é o efeito ${ }_{\epsilon}$ residual e a variável de padronização. Como o efeito da multicolinearidade foi fraco, isso é, quando o número de condições é menor que 100, segundo Cruz \& Regazzi (1997) não ocasionam problema para a análise. Esse tipo de análise considera apenas a aplicação dessa fórmula nos tratamentos e variáveis estudadas, desprezando o efeito do bloco por ser um controle local. As quatro variáveis escolhidas foram: vigor da planta (VP), número de ramos da planta (NRP), hábito de crescimento da planta (HCP) e folha cor da nervura principal em relação à cor do limbo (FCNPRCL). Cada uma dessas variáveis básicas sofreu efeito direto e indireto das variáveis explicativas que são as demais variáveis.

Os resultados da análise de trilha foram interpretados conforme indicado por Singh \& Chaudary (1979), citados por Vencovsky \& Barriga (1992), em que, basicamente, i) coeficientes de correlação e efeitos diretos (coeficientes de trilha) altos indicam que essas variáveis independentes explicam grande parte da variação da variável básica e que ii) coeficientes de correlação positivos (ou negativos), mas o efeito direto é de sinal diferente ou negligenciável, variáveis com maiores efeitos indiretos devem ser consideradas simultaneamente para explicarem a variação da variável básica. Todas as análises estatísticas foram realizadas com o uso do programa computacional genes (Cruz \& Regazzi, 1997).

\section{RESULTADOS E DISCUSSÃO}

Na Tabela 1, observam-se as correlações entre as variáveis. As correlações que apresentam valores positivos e significativos em nível de $1 \%$ de probabilidade de erro, pelo teste $\mathrm{T}$ foram (VP) X (NRP) com coeficiente de 0,4586 , o que demonstra que, quanto maior o vigor da planta, maior o número de ramos. O caráter VP também teve uma correlação significativa com FFBL $(0,3689)$, o que indica um maior vigor em plantas que apresentam maior forma da base do limbo da folha. NRP teve correlação positiva com $\operatorname{HCP}(0,4586)$ o que significa que, quanto maior o número de ramos menos ereta é a planta. E correlação negativa com FCNPRCL (-0,3901), quanto menor o número de ramos. FCNPRCL também obteve uma correlação negativa com HCP (-0,3639), pois quanto mais ereta a planta, mais clara é a cor da nervura principal em relação à cor do limbo da folha. Quanto mais ereto o hábito de crescimento da planta, maior o comprimento do pecíolo da folha, isso é o que demonstra a correlação negativa entre $\mathrm{HCP}$ e FCP $(-0,3862)$. FCP tem correlação negativa com EF $(-0,3657)$, o que significa que, quando há a presença de estípulas o pecíolo da folha é curto. Bovi et al. (1990) observaram coeficientes de correlação significativos para variáveis relacionadas com a idade e, além disso, concluíram que a seleção precoce de açaizeiro pode ser baseada na circunferência da planta e no número de perfilhos.

A redução do porte da planta é um dos aspectos principais na escolha do porta-enxerto. Plantas de menor porte favorecem os tratos culturais e ainda permitem o adensamento das plantas (Hartmann et al., 2002). Por isso é importante a utilização de porta-enxerto de menor vigor.

Segundo Furtado et al. (2002) as estimativas dos coeficientes de correlação são úteis no entendimento de um caráter complexo, como a produção, mas elas não determinam a importância relativa das influências diretas e indiretas dos outros caracteres com a produção. Isso porque a correlação entre duas características mede a associação entre ambas, entretanto, não determina a relação de causa e efeito entre elas, que pode ser determinada por meio da análise de trilha.

$\mathrm{Na}$ análise de trilha, a variável básica VP (Tabela 2), se correlaciona positivamente com HCP, RR, CETMR, NL, TL, FL, PR, FPERR, FPSTL, FFBL, FFAL, FIML e EP. Já a variável NRP tem o seu efeito indireto positivo, porém seu efeito direto é negativo, esse fato indica que a resposta correlacionada por meio da seleção indireta não será eficiente, assim como as demais que são negativas.

Segundo Sobreira et al. (2007), se apesar do efeito indireto ser positivo o efeito direto é negativo e os resultados não serão favoráveis, pois a resposta correlacionada, por meio da seleção indireta não será eficiente, devendo ser os dois efeitos positivos. Esse autores verificaram esses resultados em tomate, em que, embora a correlação da variável peso médio do fruto (PMF) com a variável resistência pós-colheita (RPC) tenha se apresentado positiva, seu efeito direto apresentou-se negativo. Esse fato indicou que a seleção indireta não será eficiente. 


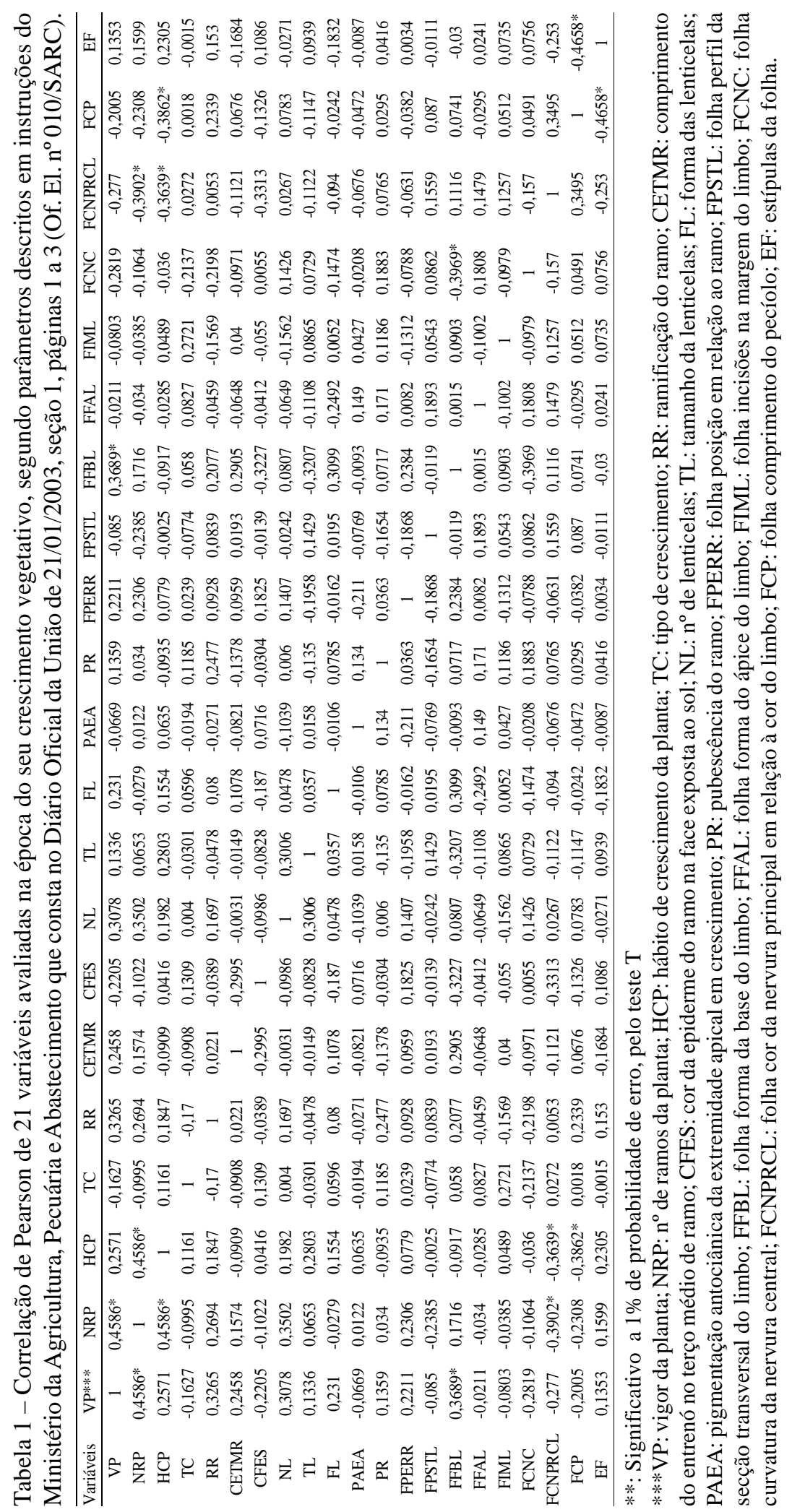


Santos et al. (2000), verificaram a influência de componentes na produção de grãos de amendoim, e constataram que o rendimento em vagens é um critério seletivo para elevar a produção de sementes no melhoramento do amendoim e a porcentagem de vagem chocha é negativamente correlacionada com o rendimento em sementes, devendo ser mantida sob controle nos processos da seleção. Sendo a análise de trilha utilizada como critério seletivo para o melhoramento da produção do amendoim.

Já segundo Kurek et al. (2001), trabalhando com correlação genética, relação direta e indireta existente entre o rendimento de grãos em feijão e os caracteres componentes do rendimento, almejando auxiliar o pesquisador no processo de seleção de plantas, constataram que, no geral, a seleção indireta a ser praticada entre os componentes primários do rendimento não parece ser uma boa estratégia para o progresso genético, uma vez que a maioria dos efeitos indiretos são negativos. Já no aspecto efeito direto sobre o rendimento, os três caracteres possibilitam a seleção indireta para incrementar esse caráter complexo que é o rendimento de grãos.

Na análise de trilha, a variável básica NRP (Tabela 3), se correlaciona positivamente com HCP, RR, CETMR, NL, PAEA, PR, FPERR, FFAL e FIML. Já VP, TL, FFBL e EF têm o seu efeito indireto positivo, porém seu efeito direto é negativo. Este fato indica que a resposta correlacionada por meio da seleção indireta não será eficiente, com as demais que são negativas.

Tabela 2 - Análise de trilha das variáveis explicativas NRP,HCP, TC, RR, CETMR, CFES, NL, TL, FL, PAEA, PR, FPERR, STL, FFBL, FFAL, FIML, FCNC, FCNPRCL, FCP e EF sobre VP.***

\begin{tabular}{clcclcc}
\hline Variáveis & Descrição dos efeitos & Estimativas & Variáveis & \multicolumn{2}{c}{ Descrição dos efeitos } & Estimativas \\
\hline \multirow{2}{*}{ NRP } & efeito direto sobre VP & -0.394 & PR & efeito direto sobre VP & 0.246 \\
& efeito indireto Total & 0,459 & & efeito indireto Total & 0.136 \\
\hline \multirow{2}{*}{ HCP } & efeito direto sobre VP & 0.03 & FPERR & efeito direto sobre VP & 0.155 \\
& efeito indireto Total & 0.257 & & efeito indireto Total & 0.221 \\
\hline \multirow{2}{*}{ TC } & efeito direto sobre VP & -0.278 & FPSTL & efeito direto sobre VP & 0.043 \\
& efeito indireto Total & -0.162 & & efeito indireto Total & -0.085 \\
\hline \multirow{2}{*}{ RR } & efeito direto sobre VP & 0.058 & FFBL & efeito direto sobre VP & 0.071 \\
& efeito indireto Total & 0.326 & & efeito indireto Total & 0.369 \\
\hline CETMR & efeito direto sobre VP & 0.084 & FFAL & efeito direto sobre VP & 0.119 \\
& efeito indireto Total & 0.246 & & efeito indireto Total & -0.021 \\
\hline \multirow{2}{*}{ CFES } & efeito direto sobre VP & -0.244 & FIML & efeito direto sobre VP & 0.33 \\
& efeito indireto Total & -0.22 & & efeito indireto Total & -0.08 \\
\hline NL & efeito direto sobre VP & 0.316 & FCNC & efeito direto sobre VP & -0.444 \\
& efeito indireto Total & 0.308 & & efeito indireto Total & -0.282 \\
\hline TL & efeito direto sobre VP & 0.07 & FCNPRCL & efeito direto sobre VP & -0.426 \\
& efeito indireto Total & 0.134 & & efeito indireto Total & -0.277 \\
\hline FL & efeito direto sobre VP & 0.051 & FCP & efeito direto sobre VP & -0.057 \\
& efeito indireto Total & 0.231 & & efeito indireto Total & -0.2 \\
\hline PAEA & efeito direto sobre VP & -0.086 & EF & efeito direto sobre VP & 0.037 \\
& efeito indireto Total & -0.067 & & efeito indireto Total & 0.135 \\
\hline
\end{tabular}

coeficiente de determinação $=0,62$

***VP: vigor da planta; NRP: $\mathrm{n}^{\circ}$ de ramos da planta; HCP: hábito de crescimento da planta; TC: tipo de crescimento; RR: ramificação do ramo; CETMR: comprimento do entrenó no terço médio de ramo; CFES: cor da epiderme do ramo na face exposta ao sol; NL: $\mathrm{n}^{\circ}$ de lenticelas; TL: tamanho da lenticelas; FL: forma das lenticelas; PAEA: pigmentação antociânica da extremidade apical em crescimento; PR: pubescência do ramo; FPERR: folha posição em relação ao ramo; FPSTL: folha perfil da secção transversal do limbo; FFBL: folha forma da base do limbo; FFAL: folha forma do ápice do limbo; FIML: folha incisões na margem do limbo; FCNC: folha curvatura da nervura central; FCNPRCL: folha cor da nervura principal em relação a cor do limbo; FCP: folha comprimento do pecíolo; EF: estípulas da folha. 
Tabela 3 - Análise de trilha das variáveis explicativas VP,HCP, TC, RR, CETMR, CFES, NL, TL, FL, PAEA, PR, FPERR, FPSTL, FFBL, FFAL, FIML, FCNC, FCNPRCL, FCP e EF sobre NRP.***

\begin{tabular}{clcclc}
\hline Variáveis & Descrição dos efeitos & Estimativas & Variáveis & \multicolumn{1}{c}{ Descrição dos efeitos } & Estimativas \\
\hline \multirow{2}{*}{ VP } & efeito direto sobre NRP & -0.043 & PR & efeito direto sobre NRP & 0.009 \\
& efeito indireto Total & 0.458 & & efeito indireto Total & 0.034 \\
\hline \multirow{2}{*}{ HCP } & efeito direto sobre NRP & 0.148 & FPERR & efeito direto sobre NRP & 0.176 \\
& efeito indireto Total & 0.399 & & efeito indireto Total & 0.23 \\
\hline \multirow{2}{*}{ TC } & efeito direto sobre NRP & -0.157 & FPSTL & efeito direto sobre NRP & -0.106 \\
& efeito indireto Total & -0.099 & & efeito indireto Total & -0.238 \\
\hline \multirow{2}{*}{ RR } & efeito direto sobre NRP & 0.241 & FFBL & efeito direto sobre NRP & -0.012 \\
& efeito indireto Total & 0.269 & & efeito indireto Total & 0.172 \\
\hline CETMR & efeito direto sobre NRP & 0.44 & FFAL & efeito direto sobre NRP & 0.036 \\
& efeito indireto Total & 0.157 & & efeito indireto Total & -0.034 \\
\hline \multirow{2}{*}{ CFES } & efeito direto sobre NRP & -0.278 & FIML & efeito direto sobre NRP & 0.167 \\
& efeito indireto Total & -0.102 & & efeito indireto Total & -0.038 \\
\hline \multirow{2}{*}{ NL } & efeito direto sobre NRP & 0.383 & FCNC & efeito direto sobre NRP & -0.179 \\
& efeito indireto Total & 0.35 & & efeito indireto Total & -0.106 \\
\hline \multirow{2}{*}{ TL } & efeito direto sobre NRP & -0.105 & FCNPRCL & efeito direto sobre NRP & -0.489 \\
& efeito indireto Total & 0.065 & & efeito indireto Total & -0.39 \\
\hline FL & efeito direto sobre NRP & -0.207 & FCP & efeito direto sobre NRP & -0.152 \\
& efeito indireto Total & -0.028 & & efeito indireto Total & -0.23 \\
\hline PAEA & efeito direto sobre NRP & 0.013 & EF & efeito direto sobre NRP & -0.111 \\
& efeito indireto Total & 0.012 & & efeito indireto Total & 0.159 \\
\hline
\end{tabular}

coeficiente de determinação=0,56

***VP: vigor da planta; NRP: $\mathrm{n}^{\circ}$ de ramos da planta; HCP: hábito de crescimento da planta; TC: tipo de crescimento; RR: ramificação do ramo; CETMR: comprimento do entrenó no terço médio de ramo; CFES: cor da epiderme do ramo na face exposta ao sol; NL: $\mathrm{n}^{\circ}$ de lenticelas; TL: tamanho da lenticelas; FL: forma das lenticelas; PAEA: pigmentação antociânica da extremidade apical em crescimento; PR: pubescência do ramo; FPERR: folha posição em relação ao ramo; FCL: folha comprimento do limbo; FRCL: folha relação comprimento largura; FPSTL: folha perfil da secção transversal do limbo; FFBL: folha forma da base do limbo; FFAL: folha forma do ápice do limbo; FIML: folha incisões na margem do limbo; FCNC: folha curvatura da nervura central; FCNPRCL: folha cor da nervura principal em relação a cor do limbo; FCP: folha comprimento do pecíolo; EF: estípulas da folha.

Na análise de trilha, a variável básica HCP (Tabela 4), se correlaciona positivamente com VP, NRP, TC, RR, NL, TL, FL, PAEA, FPERR, FPSTL, FFAL, FIML, FCNC e EF. Já CFES tem o seu efeito indireto positivo, porém seu efeito direto é negativo. Este fato indica que a resposta correlacionada por meio da seleção indireta não será eficiente, com as demais que são negativas.

Segundo Gomes et al. (2007) que calcularam os coeficientes de trilha entre a produção de raízes tuberosas e cinco componentes da produção, de modo a auxiliar na seleção de clones superiores. Esses autores constataram que o número de raízes tuberosas, por planta, e o peso total da parte aérea podem ser utilizados como critérios auxiliares na seleção de clones mais produtivos.
$\mathrm{Na}$ análise de trilha, a variável básica FCNPRCL (Tabela 5), se correlaciona positivamente com RR, NL, PR, FPERR, FPSTL, FFAL, FIML e FCP. Já TC e FFBL têm o seu efeito indireto positivo, porém seu efeito direto é negativo. Esse fato indica que a resposta correlacionada por meio da seleção indireta não será eficiente, com as demais que são negativas.

A variáveis número de lenticelas teve um efeito direto positivo e de elevada magnitude para VP (Tabela 2), NRP (Tabela 3), e FCNPRCL (Tabela 5). Assim, para essas variável o número de lenticelas é o fator de seleção mais eficaz. Já para HCP, a variável que apresentou o efeito direto positivo e de bastante relevância foi a ramificação do ramo, como podemos observar na tabela 4. Essa variável é o fator de seleção mais eficaz para essa variável básica. 
Tabela 4 - Análise de trilha das variáveis explicativas VP, NRP, TC, RR, CETMR, CFES, NL, TL, FL, PAEA, PR, FPERR, FPSTL, FFBL, FFAL, FIML, FCNC, FCNPRCL, FCP e EF sobre HCP.***

\begin{tabular}{clcclc}
\hline Variáveis & Descrição dos efeitos & Estimativas & Variáveis & Descrição dos efeitos & Estimativas \\
\hline VP & efeito direto sobre HCP & 0.048 & PR & efeito direto sobre HCP & -0.334 \\
& efeito indireto Total & 0.257 & & efeito indireto Total & -0.093 \\
\hline \multirow{2}{*}{ NRP } & efeito direto sobre HCP & 0.289 & FPERR & efeito direto sobre HCP & 0.139 \\
& efeito indireto Total & 0.458 & & efeito indireto Total & 0.077 \\
\hline \multirow{2}{*}{ TC } & efeito direto sobre HCP & 0.213 & FPSTL & efeito direto sobre HCP & 0.094 \\
& efeito indireto Total & 0.116 & & efeito indireto Total & -0.002 \\
\hline \multirow{2}{*}{ RR } & efeito direto sobre HCP & 0.319 & FFBL & efeito direto sobre HCP & -0.167 \\
& efeito indireto Total & 0.185 & & efeito indireto Total & -0.092 \\
\hline CETMR & efeito direto sobre HCP & -0.193 & FFAL & efeito direto sobre HCP & 0.005 \\
& efeito indireto Total & -0.09 & & efeito indireto Total & -0.028 \\
\hline CFES & efeito direto sobre HCP & -0.157 & FIML & efeito direto sobre HCP & 0.266 \\
& efeito indireto Total & 0.041 & & efeito indireto Total & 0.049 \\
\hline \multirow{2}{*}{ NL } & efeito direto sobre HCP & 0.04 & FCNC & efeito direto sobre HCP & 0.077 \\
& efeito indireto Total & 0.198 & & efeito indireto Total & -0.036 \\
\hline TL & efeito direto sobre HCP & 0.088 & FCNPRCL & efeito direto sobre HCP & -0.158 \\
& efeito indireto Total & 0.28 & & efeito indireto Total & -0.363 \\
\hline FL & efeito direto sobre HCP & 0.166 & FCP & efeito direto sobre HCP & -0.367 \\
& efeito indireto Total & 0.155 & & efeito indireto Total & -0.386 \\
\hline PAEA & efeito direto sobre HCP & 0.123 & EF & efeito direto sobre HCP & -0.132 \\
& efeito indireto Total & 0.063 & & efeito indireto Total & 0.23 \\
\hline
\end{tabular}

coeficiente de determinação= $=0,57$

***VP: vigor da planta; NRP: $\mathrm{n}^{\text {o }}$ de ramos da planta; HCP: hábito de crescimento da planta; TC: tipo de crescimento; RR: ramificação do ramo; CETMR: comprimento do entrenó no terço médio de ramo; CFES: cor da epiderme do ramo na face exposta ao sol; NL: $\mathrm{n}^{\circ}$ de lenticelas; TL: tamanho da lenticelas; FL: forma das lenticelas; PAEA: pigmentação antociânica da extremidade apical em crescimento; PR: pubescência do ramo; FPERR: folha posição em relação ao ramo; FPSTL: folha perfil da secção transversal do limbo; FFBL: folha forma da base do limbo; FFAL: folha forma do ápice do limbo; FIML: folha incisões na margem do limbo; FCNC: folha curvatura da nervura central; FCNPRCL: folha cor da nervura principal em relação a cor do limbo; FCP: folha comprimento do pecíolo; EF: estípulas da folha.

Segundo Vieira et al. (2007) estudando as correlações genéticas e os seus desdobramentos em efeitos diretos e indiretos, de componentes primários e secundários sobre o rendimento de grãos em 19 genótipos de trigo, constataram que fatores primários, como número de grãos por espigueta e o número de afilhos por metro linear, apresentam maior importância na determinação do rendimento de grãos. Os caracteres secundários que, isoladamente, apresentam maior importância em explicar as variações no rendimento de grãos são a estatura de planta e o número de dias da emergência à maturação.

Os coeficientes de determinação $\left(\mathrm{R}^{2}\right)$ ficaram entre 0,57 e 0,67 , o que dá maior confiabilidade aos resultados. Alves et al. (2003) ao encontrarem coeficientes de determinação superiores a 0,5 , para descritores de cupuaçuzeiro, afirmaram que esses valores reforçam a confiabilidade dos descritores.

As variáveis que possuem efeito direto positivo com as quatro variáveis básicas (vigor da planta (VP), número de ramos da planta (NRP), hábito de crescimento da planta (HCP) e folha cor da nervura principal em relação à cor do limbo (FCNPRCL)) são: Ramo de um ano: ramificação (RR), Ramo de um ano: número de lenticelas (NL), folha posição em relação ao ramo (FPERR) e Folha: forma do ápice do limbo (excluindo a ponta) (FFAL). Segundo Severino et al. (2002), para fins de melhoramento, é importante identificar, dentre as características de alta correlação com a variável básica, aquelas de maior efeito direto, no sentido favorável à seleção, de tal forma que a resposta correlacionada por meio da seleção indireta seja eficiente. 
Tabela 5 - Análise de trilha das variáveis explicativas VP, NRP, HCP, TC, RR, CETMR, CFES, NL, TL, FL, PAEA, PR, FPERR, FPSTL, FFBL, FFAL, FIML, FCNC, , FCP e EF sobre FCNPRCL.***

\begin{tabular}{|c|c|c|c|c|c|}
\hline Variáveis & Descrição dos efeitos & Estimativas & Variáveis & Descrição dos efeitos & Estimativas \\
\hline \multirow{3}{*}{ VP } & efeito direto sobre & & & efeito direto sobre & \\
\hline & FCNPRCL & -0.382 & PAEA & FCNPRCL & -0.026 \\
\hline & efeito indireto Total & -0.277 & & efeito indireto Total & -0.067 \\
\hline \multirow{3}{*}{ NRP } & efeito direto sobre & & & efeito direto sobre & \\
\hline & FCNPRCL & -0.375 & PR & FCNPRCL & 0.094 \\
\hline & efeito indireto Total & -0.39 & & efeito indireto Total & 0.076 \\
\hline \multirow{3}{*}{$\mathrm{HCP}$} & efeito direto sobre & & & efeito direto sobre & \\
\hline & FCNPRCL & -0.116 & FPERR & FCNPRCL & 0.214 \\
\hline & efeito indireto Total & -0.364 & & efeito indireto Total & -0.063 \\
\hline \multirow{3}{*}{$\mathrm{TC}$} & efeito direto sobre & & & efeito direto sobre & \\
\hline & FCNPRCL & -0.196 & FPSTL & FCNPRCL & 0.142 \\
\hline & efeito indireto Total & 0.027 & & efeito indireto Total & 0.155 \\
\hline \multirow{3}{*}{$\mathrm{RR}$} & efeito direto sobre & & & efeito direto sobre & \\
\hline & FCNPRCL & 0.061 & FFBL & FCNPRCL & -0.077 \\
\hline & efeito indireto Total & 0.005 & & efeito indireto Total & 0.111 \\
\hline \multirow{3}{*}{ CETMR } & efeito direto sobre & & & efeito direto sobre & \\
\hline & FCNPRCL & -0.134 & FFAL & FCNPRCL & 0.082 \\
\hline & efeito indireto Total & -0.112 & & efeito indireto Total & 0.147 \\
\hline \multirow{3}{*}{ CFES } & efeito direto sobre & & & efeito direto sobre & \\
\hline & FCNPRCL & -0.502 & FIML & FCNPRCL & 0.239 \\
\hline & efeito indireto Total & -0.331 & & efeito indireto Total & 0.125 \\
\hline \multirow{3}{*}{ NL } & efeito direto sobre & & & efeito direto sobre & \\
\hline & FCNPRCL & 0.376 & FCNC & FCNPRCL & -0.468 \\
\hline & efeito indireto Total & 0.026 & & efeito indireto Total & -0.157 \\
\hline \multirow{3}{*}{$\mathrm{TL}$} & efeito direto sobre & & & efeito direto sobre & \\
\hline & FCNPRCL & -0.104 & FCP & FCNPRCL & 0.015 \\
\hline & efeito indireto Total & -0.112 & & efeito indireto Total & 0.349 \\
\hline \multirow{3}{*}{ FL } & efeito direto sobre & & & efeito direto sobre & \\
\hline & FCNPRCL & -0.131 & $\mathrm{EF}$ & FCNPRCL & -0.135 \\
\hline & efeito indireto Total & -0.094 & & efeito indireto Total & -0.253 \\
\hline
\end{tabular}

coeficiente de determinação= 0,67

***VP: vigor da planta; NRP: $\mathrm{n}^{\circ}$ de ramos da planta; HCP: hábito de crescimento da planta; TC: tipo de crescimento; RR: ramificação do ramo; CETMR: comprimento do entrenó no terço médio de ramo; CFES: cor da epiderme do ramo na face exposta ao sol; NL: ${ }^{\circ}$ de lenticelas; TL: tamanho das lenticelas; FL: forma das lenticelas; PAEA: pigmentação antociânica da extremidade apical em crescimento; PR: pubescência do ramo; FPERR: folha posição em relação ao ramo; FPSTL: folha perfil da secção transversal do limbo; FFBL: folha forma da base do limbo; FFAL: folha forma do ápice do limbo; FIML: folha incisões na margem do limbo; FCNC: folha curvatura da nervura central; FCNPRCL: folha cor da nervura principal em relação a cor do limbo; FCP: folha comprimento do pecíolo; EF: estípulas da folha.

Nota-se que o número de lenticelas e ramificação de ramo correlacionam-se positivamente com a variável básica e apresentam efeitos diretos positivos e altos sobre essa característica, além de efeitos indiretos negativos mínimos sobre a variável básica (Gomes et al., 2007), o que sugere a utilização dos mesmos como auxiliares na seleção para obtenção de porta-enxertos de Pyrus communis. De La Rosa et al. (2006) observaram que o vigor dos seedlings pode ser usado como critério de seleção para redução no período de juvenilidade, no melhoramento de oliveira. 


\section{CONCLUSÕES}

As variáveis identificadas como principais pela correlação de Pearson foram vigor da planta (VP), número de ramos da planta (NRP), hábito de crescimento da planta (HCP) e folha: cor da nervura principal em relação à cor do limbo (FCNPRCL);

As variáveis Ramo de um ano: ramificação (RR), Ramo de um ano: número de lenticelas (NL), folha posição em relação ao ramo (FPERR) e Folha: forma do ápice do limbo (excluindo a ponta) (FFAL), podem ser usadas com sucesso na seleção das plantas candidatas a porta-enxerto para pereira.

\section{AGRADECIMENTOS}

À Coordenação de Aperfeiçoamento de Pessoal de Nível Superior (CAPES) e ao CNPq pelo apoio, através da concessão de bolsas aos pesquisadores deste projeto.

\section{REFERÊNCIAS BIBLIOGRÁFICAS}

ALVES, R.M.; GARCIA, A.A.F.; CRUZ, E.D.; FIGUEIRA, A. Seleção de descritores botânico-agronômicos para caracterização de germoplasma de cupuaçuzeiro. Pesquisa Agropecuária Brasileira, Brasília, v.38, n.7, p.807-818, jul. 2003.

BARBOSA, W. et al. Desenvolvimento de mudas de pereira enxertadas em plântulas do porta-enxerto Taiwan Nashi-C. In: CONGRESSO BRASILEIRO DE FRUTICULTURA, 13., 1994, Salvador. Resumos... Salvador, 1994. p. 857-858.

BOVI, M.L.A.; GODOY JUNIOR, G.; SPIERING, S.H.; CAMARGO, S.B. de. Correlações fenotípicas entre caracteres avaliados nos estádios juvenil e adulto de açaizeiros. Bragantia, Campinas, v.49, n.2, p.321-334, 1990.

CAIERÃO, E.; CARVALHO, F.I.F.; PACHECO, M.T.

Seleção indireta em aveia para o incremento no rendimento de grãos. Ciência Rural, Santa Maria, v.31, n.32 p.231-236, 2001.

CARVALHO, C.G.P.; OLIVEIRA, V.R.; CRUZ, C.D. Análise de trilha sob multicolinearidade em pimentão. Pesquisa Agropecuária Brasileira, Brasília, v.34, n.4, p.603-613, abr. 1999.

COIMBRA, J.L.M.; BENIN, G.; VIEIRA, E.A.

Conseqüências da multicolinearidade sobre a análise de trilha em canola. Ciência Rural, Santa Maria, v.35, n.2, p.347-352, 2005.
CRUZ, C.D. Programa GENES versão Windows: aplicativo computacional em genética e estatística. Viçosa, MG: UFV, 2001. 648p.

CRUZ, C.D.; REGAZZI, A.J. Modelos biométricos aplicados ao melhoramento genético. Viçosa, MG: UFV, 1997. 390p.

DE LA ROSA, R.; KIRAN, A.I.; BARRANCO, D.; LEON, L. Seedling vigour as a preselection criterion for short juvenile period in olive breeding. Australian Journal of Agricultural Research, Collingwood, v.57, n.4, p.477-481, 2006.

FURTADO, M.R.; CRUZ, C.D.; CARDOSO, A.A.; COELHO, A.D.F.; PETERNELLI, L.A. Análise de trilha do rendimento do feijoeiro e seus componentes primários em monocultivo e em consórcio com a cultura do milho. Ciência Rural, Santa Maria, v.32, n.2, p.217-220, abr./jun. 2002.

GIACOBBO, C.L.; FACHINELLO, J.C.; PICOLOTTO, L. Compatibilidade entre marmeleiro port-enxerto cv. EMC e cultivares de pereira. Scientia Agraria, Curitiba, v.8, n.1, p.33-37, 2007.

GOMES, C.N.; ASSIS, L.H.B.; CARVALHO, M.; CARVALHO, S.P. Coeficientes de trilha de caracteres componentes da produção em mandioca. Lavras: UFLA, 2007.

JOÃO, P.L.; ROSA, J.I.; FERRI, V.C.; MARTINELLO, M.D. Levantamento da fruticultura comercial do Rio Grande do Sul. Realidade Rural, Porto Alegre, v.28, p.17, 2002.

HARTMANN, H.T.; KESTER, F.T.; DAVIES JUNIOR, R.L. Plant propagation: principles and practices. New Jersey: Prentice Hall, 2002. 880p.

KUREK, A.; CARVALHO, F.I.F.; ASSMANN, I.C. Análise de trilha como critério de seleção indireta para rendimento de grãos em feijão. Revista Brasileira de Agrociência, Pelotas, v.7, n.1, p.29-32, 2001.

LACEY, C.N.D. Phenotypic correlations between vegetative characters and yield components in strawberry. Euphytica, Wageningen, v.22, n.3, p.546554, 1973. 
MADAIL, J.C.M.; REICHERT, L.J. Aspectos econômicos das principais frutas de clima temperado: pêssego, nectarina, maçã, ameixa, pêra e morango. Pelotas: Embrapa Clima Temperado, 2002. Comunicado técnico.

PERAZZOLO, G. Tecnologia para a produção de pêras européias. In: ENCONTRO NACIONAL SOBRE FRUTICULTURA DE CLIMA TEMPERADO, 9., 2006, Fraiburgo. Anais... Fraiburgo, 2006. p.109-115.

RIBEIRO JÚNIOR, J.I. Análises estatísticas no SAEG. Viçosa, MG: UFV, 2001.

SANTOS, R.C.; CARVALHO, L.P.; SANTOS, V.F. Análise de coeficiente de trilha para os componentes de produção em amendoim. Ciência e Agrotecnologia, Lavras, v.24, n.1, p.13-16, jan./mar. 2000.

SEVERINO, L.S.; SAKIYAMA, N.S.; PEREIRA, A.A.; MIRANDA, G.V.M.; ZAMBOLIM, L.; BARROS, U.V.

Associação da produtividade com outras características agronômicas de café (Coffea arabica L. "Catimor"). Acta Scientiarum Agronomy, Maringá, v.24, n.5, p.1467-1471, out. 2002.

SOBREIRA, F.M.; SOBREIRA, F.M.; LOPES, F.S.; CONTARATO, C.C.; MATTA, F.P. Análise de trilha em caracteres relacionados à resistência pós-colheita de tomate tipo salada Lycopersicon esculentum. In: ENCONTRA LATINO AMERICANO DE INICIAÇÃO CIENTÍFICA, 11.; ENCONTRO LATINO AMERICANO DE PÓS-GRADUAÇÃO DA UNIVERSIDADE DO VALE DO PARAÍBA, 7., 2007, Areia. Anais... Areia, 2007. Disponível em: Uhttp://WWW.inicepg.univap.bri INIC_ 07 trabalhos/trabalhos05.htmly. Acesso em: 6 mar. 2008.

VENCOVSKY, R.; BARRIGA, P. Genética biométrica no fitomelhoramento. Ribeirão Preto: USP, 1992. 496p

VIEIRA, E.A.; CARVALHO, F.I.F. de; OLIVEIRA, A.C. de; MARTINS, L.F.; BENIN, G.; SILVA, J.A.G. da; COIMBRA, J.; MARTINS, A.F.; CARVALHO, M.F. de; RIBEIRO, G. Análise de trilha entre os componentes primários e secundários do rendimento de grãos em trigo. Revista Brasileira de Agrociência, Pelotas, v.13, n.2, p.169-174, 2007.

WERTHEIM, S.J. Rootstocks for european pear: A reiview. Acta Horticulturae, Leuven, n.596, p.299-309, 2002.

WRIGHT, S. Correlation and causation. Journal of Agriculture, Washington, v.20, p.557-85, 1921. 